BMJ Open Sport \& Exercise Medicine

\title{
Association of artificial turf and concussion in competitive contact sports: a systematic review and meta- analysis
}

\author{
Frank O' Leary (D) , ${ }^{1}$ Nic Acampora, ${ }^{2}$ Fiona Hand, ${ }^{3}$ James O' Donovan ${ }^{1}$
}

\begin{abstract}
To cite: $0^{\prime}$ Leary F, Acampora $\mathrm{N}$, Hand $\mathrm{F}$, et al. Association of artificial turf and concussion in competitive contact sports: a systematic review and meta-analysis. BMJ Open Sport \& Exercise Medicine 2020;6:e000695. doi:10.1136/ bmjsem-2019-000695
\end{abstract}

- Additional material is published online only. To view please visit the journal online (http://dx.doi.org/10.1136/ bmjsem-2019-000695).

Accepted 9 May 2020

\section{Check for updates}

(c) Author(s) (or their employer(s)) 2020. Re-use permitted under CC BY-NC. No commercial re-use. See rights and permissions. Published by BMJ.

${ }^{1}$ Department of Performance Medicine, Sport Ireland Institute, Dublin, Ireland

${ }^{2}$ Faculty of Life Sciences, University of South Wales, Pontypridd, UK

${ }^{3}$ Department of Surgery, St. Vincent's University Hospital, Elm Park, Dublin, Ireland

Correspondence to Dr Frank 0' Leary; foleary@instituteofsport.ie

\section{ABSTRACT}

Objective To determine the incidence of head injuries and concussion in contact sports, comparing natural grass with artificial turf surfaces.

Design Systematic review and meta-analysis via the RevMan V.5.3 software.

Eligibility criteria for selecting studies All studies describing competitive contact sports played on both natural grass and artificial turf. The primary outcome measured was occurrence of head injury and concussion. Data sources The databases include PubMed, Embase, Cochrane, Medline and Sport Discus. The last search took place on 23 May 2019. The Newcastle-Ottawa Quality Assessment Scale evaluated the methodological quality of the selected studies with a funnel plot designed to determine publication bias. Study screening and data extraction were performed by two independent reviewers. Results Initial screening generated 42 publications, with 12 meeting criteria for inclusion. Eight studies described concussion only. The rate ratio (RR) of head injury and concussion was less on artificial turf compared with natural grass ( $\mathrm{RR}=0.89,95 \% \mathrm{Cl} 0.77$ to 1.04$)$ as was the rate ratio of concussion only ( $\mathrm{RR}=0.72,95 \% \mathrm{Cl} 0.58$ to 0.89).

Conclusion Analysis of published data demonstrates a decreased incidence of head injury and concussion when contact sports are played on artificial turf. This difference was most marked for sports such as rugby and American football. However, artificial turf has no association with the incidence of head injury or concussion while playing soccer.

\section{INTRODUCTION}

Artificial turf can be defined as 'a surface of synthetic fibres made to look like natural grass'. 1

Since its introduction in 1965, safety concerns have been raised over its use as a playing surface in competitive contact sports. ${ }^{23}$ The higher number of knee and ankle injuries occurring on artificial turf has been established. ${ }^{4}$

Despite these safety concerns, an ongoing replacement of natural grass with synthetic turf continues to occur in contact sport. ${ }^{5}$

\section{What is already known?}

With increasing awareness of head injuries in contact sports, the diagnosis of concussion is becoming more common. Artificial turf is frequently used as a playing surface for contact sports. There remains no consensus on whether playing surface contributes to the incidence of significant head injury.

\section{What are the new findings?}

Analysis of the limited publications on artificial turf playing surface demonstrates a lower incidence of concussion and head injury in competitive contact sports. On subgroup analysis, this effect is most marked in rugby and American football, with no significant association of playing surface on the incidence of head injury or concussion in soccer.

Its use is also becoming more accepted at international level. This was highlighted by a controversial decision in 2014 when both the UEFA and FIFA sanctioned the use of artificial turf for major soccer competitions. ${ }^{6}$ Similarly, World Rugby, identifying the increasing use of synthetic surfaces in its sport, last updated 'Regulation 22' in 2017 detailing specific criteria for which the artificial playing surface must meet, in order that it be deemed playable. ${ }^{7}$ This publication also highlighted the requirement to regularly maintain synthetic playing surfaces in order to minimise player injury. Certain environmental factors have shown to negatively impact the shock absorption of artificial turf, for example, cold temperature. $^{8}$

The diagnosis of sports-related concussion (a traumatic brain injury induced by biomechanical forces) ${ }^{9}$ appears to have increased over the past decade, with up to 3.8 million sports-related concussions reported per annum in the USA alone. ${ }^{10}$ However, due to changes in the diagnosis of concussion over 
time and its increased public awareness, the correlation between concussion incidence and the actual injury rates remain elusive. This has resulted in a significant variation in concussion injury rates documented in the literature. ${ }^{11}$ Other factors contributing to this apparent higher incidence would include an improved understanding of the condition among sports physicians as well as the formulation and integration of rigorous protocols for head injury assessment. ${ }^{12}$ The incidence of concussion occurring on artificial turf due to player head to surface contact varies in the literature, from under $6 \%$ to as high as $30 \% .{ }^{13} \mathrm{~A}$ clear link between artificial turf and concussion (or head injuries) has yet to be established in contact sport.

The aim of this review was to compare the incidence of head injuries and concussion on both artificial turf and natural grass in those competitive contact sports (of any standard) using both surfaces. From this, the risk of such injuries can be directly compared on either playing surface.

\section{METHODS}

\section{Study design}

This systematic review and meta-analysis examines the rate of concussion and head injury in athletes who play competitive contact sports on artificial turf in comparison with natural grass. The review is reported according to the Preferred Reporting Items for Systematic Reviews and Meta-Analyses guidelines ${ }^{15}$ and will be guided by the Meta-analysis of Observational Studies in Epidemiology reporting guidelines. ${ }^{16}$ For the purpose of this systematic review, 'competitive' contact sports include only the matches of the relevant sports.

\section{Search strategy}

Electronic research databases used for this systematic literature search included PubMed, Embase, Cochrane, Medline and Sport Discus. The last search took place on 23 May 2019, and no language restrictions were set. Search terms were based on three broad categories including the 'head injury' occurring to the athlete, the 'playing surface' the sport was being played on and the 'contact sport' that was being played. A MeSH or Emtree vocabulary was used in the relevant search engines to appropriately index the journal articles. A full list of search terms and key words is supplied in online supplementary appendix 1 . Due to significant revisions in the manufacture of artificial turf since its introduction, only articles published since 1999 were included in this search.

\section{Eligibility criteria}

Studies involving male or female athletes (of any standard) who played competitive contact sport on natural grass and artificial turf were included in this review. The studies were required to directly compare head injuries or concussions occurring on both artificial turf and natural grass over a non-specified period of time.

All articles were screened to include peer-reviewed observational studies. Reference lists from each selected study were also reviewed. If a reference was deemed relevant but not found on the original search, it was subsequently included for further analysis.

\section{Study selection}

Titles and abstracts of all potentially relevant articles were screened for suitability.

Case reports, reviews, book chapters, dissertations, poster and oral conference abstracts and non-peer reviewed articles were excluded. Studies that described sports played on alternative artificial surfaces (eg, ice hockey, wrestling, tennis and basketball) were also removed. Further studies were excluded on the basis of injuries sustained in training (as opposed to competition) or if the study did not differentiate between training and match injuries. Studies that did not directly compare artificial turf with natural grass were also excluded.

If studies had a combined anatomical injury with the head, for example, 'head/neck' or 'head/face', then these studies were included in the criteria and were all presumed to describe the same injury, that is, 'head injury'. This is due to the increasing evidence of cervical spine involvement in concussion symptoms, whereby, the primary symptom can arise from the neck, for example, neck pain or neck stiffness. ${ }^{17}$ By excluding these injuries, one could limit the actual number of relevant injuries. If an included study documented both concussion and 'head injury' rates (as defined above) separately, then concussion rates were chosen as the preferential outcome. The aim of the study wants to assess concussion or suspected concussion incidence. If the study already differentiated a concussion from a head/neck or head/ face injury, then the concussion data became the most relevant.

Two reviewers (FH and FO) screened titles, abstracts and full texts (if required) independently. In the case of disagreement for selection, both reviewers discussed until a resolution. Failure of this, referral to another author (JO) was made, whereby a discussion and consultation occurred to resolve any differences. From appropriate study selection and exclusion, a flow chart was created (figure 1).

\section{Data extraction}

Data extraction took place by two independent reviewers (FO and FH) who documented relevant data on separate excel spreadsheets.

Data sought from each study included information on the year of publication, main author and country (or countries) where the participant(s) sports team are based. The details sought included the sport described, injuries of interest, type of playing surface, athletic level, gender of participants and number of match playing hours that occurred per surface. The injuries extracted from each paper included concussion rates and head injury rates or any combined anatomical injury with the head, for example, head/neck injury and head/face injury, which were subsequently labelled 'head injuries'. 


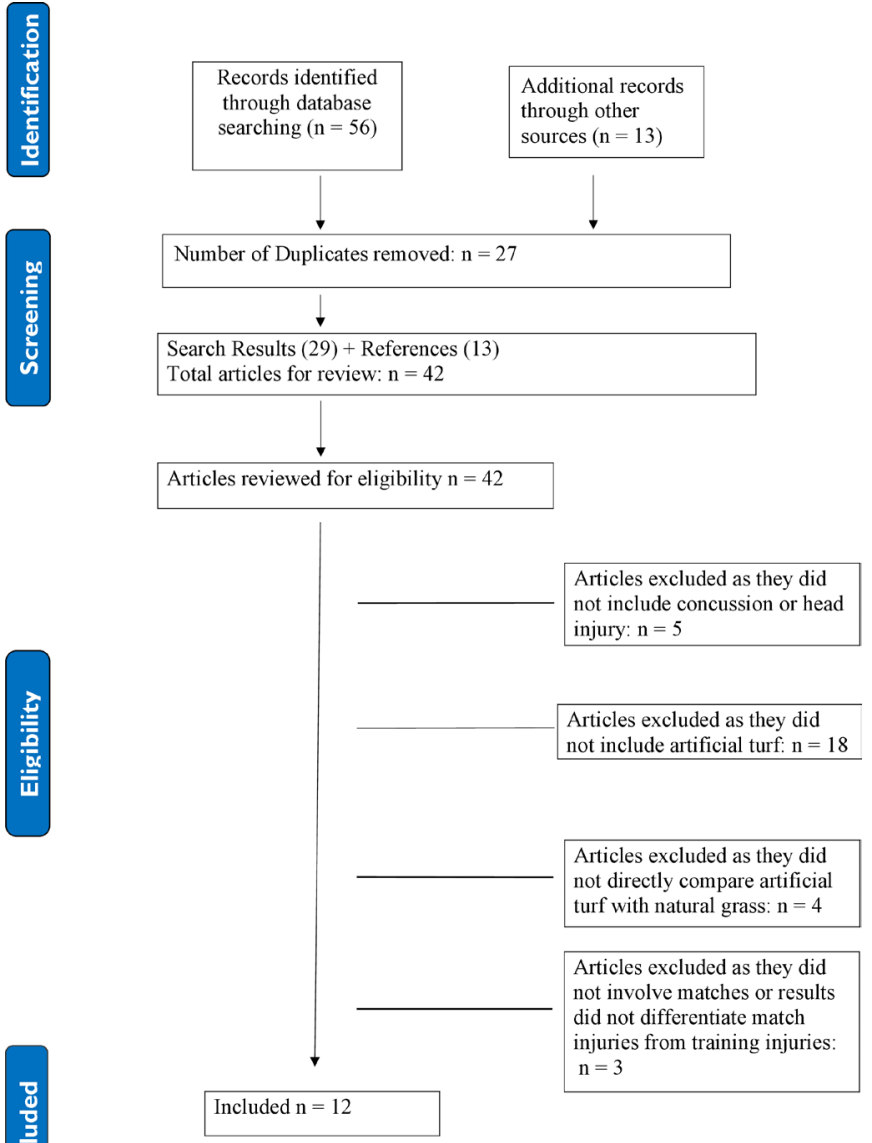

Figure 1 Systematic review: flow chart.

\section{Statistical analysis}

The primary outcome included head injuries and concussion. The secondary outcome specified concussion only. This was conducted to determine if any comparable incidence between either outcome could be found. Other subgroup analyses included assessing individual sports and assessing female athletes. Each individual sport was reviewed in order to assess any noticeable difference in head injury or concussion rates between sports. Although all sports chosen are deemed contact sports, some sports would have a higher collision element, for example, American football and rugby, compared with soccer.

Female athletes were chosen as a subgroup as there are a number of studies ${ }^{18-20}$ suggesting that female athletes have a higher risk of concussion compared with their male counterparts. The reasons are still speculative but appear to be multifactorial involving biomechanical, hormonal and cultural factors. The aim was to determine whether surface properties (ie, artificial turf or natural grass) played a role in the rates of head injuries or concussions in those female athletes who partake in competitive contact sport. Studies that included male and female athletes had its data extracted separately by gender. Such results were documented twice in the meta analyses (figures 2 and 3). The female data were labelled (F) after the author's surname, with the male data labelled (M). Injury incidences from these relevant papers were adjusted and documented to account for this data separation. If a study included female participants but the female data were not documented separately in a study, the author was contacted for clarification.

All relevant articles were analysed. From each study, the sum of documented head injuries or concussions and the number of match playing hours were extracted from both the artificial turf and natural grass group. From these data, the rate ratio (RR) was calculated. As per Cochrane effect measures for counts and rates, RR is the ratio of the rate (event/years) in the artificial turf group divided by the rate (event/years) in the natural grass group. This is then log-transformed. The Standard Error (SE) was also calculated (square root of the reciprocal of rate 1 plus rate 2$){ }^{21}$

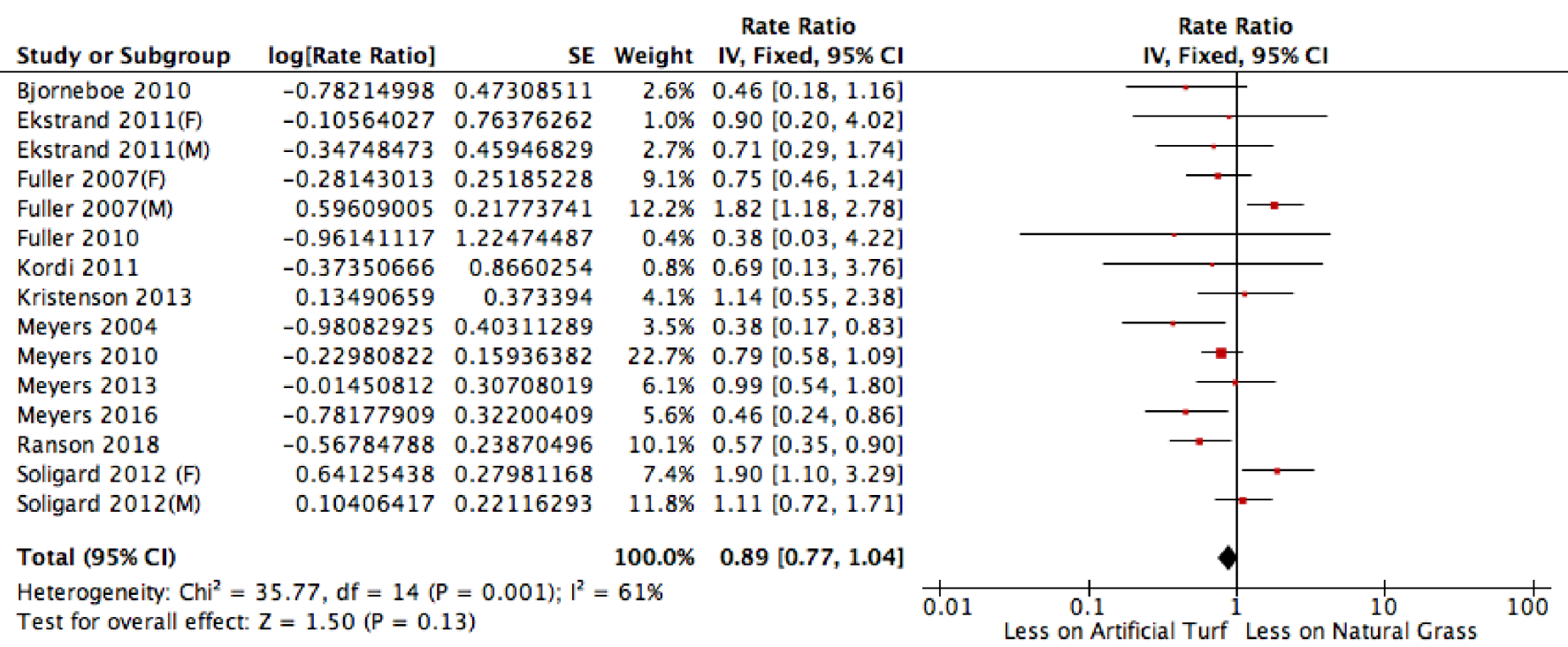

Figure 2 Forest plot: head injury and concussion risk: artificial turf versus natural grass in competitive contact sports. ' $M$ ' indicates results for male athletes in that particular study. ' $F$ ' indicates results for female athletes in that particular study. 


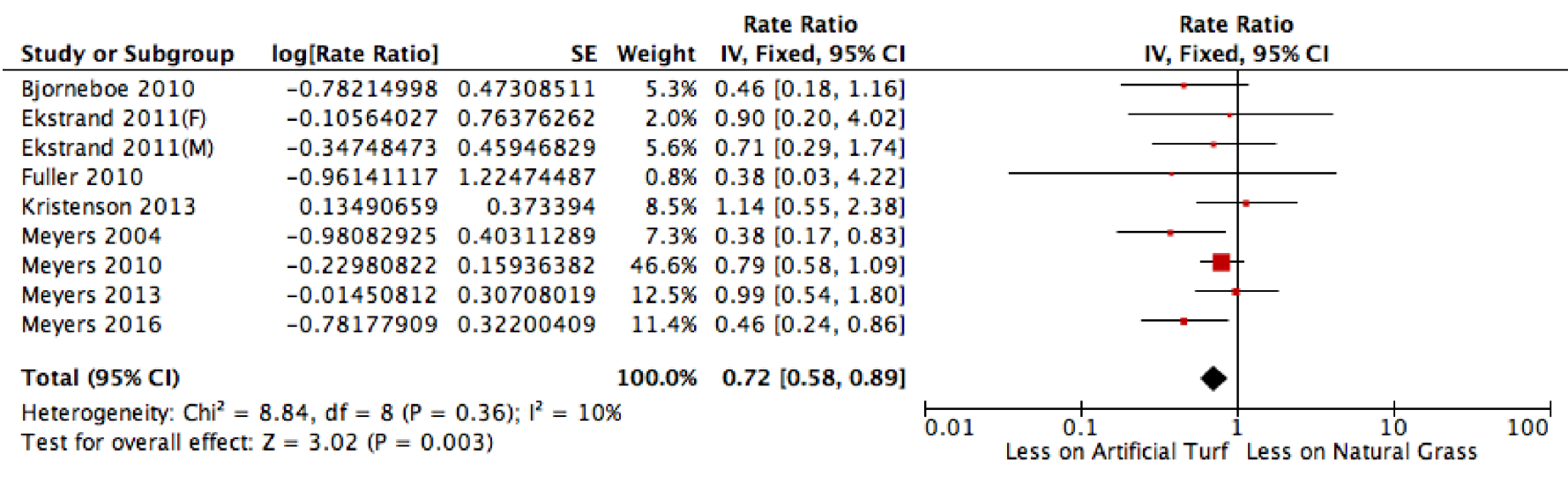

Figure 3 Forest plot: concussion risk: artificial turf versus natural grass in competitive contact sports. ' $M$ ' indicates results for male athletes in that particular study. ' $F$ ' indicates results for female athletes in that particular study.

RevMan software V.5.3 $3^{22}$ was used to: (A) construct the meta-analyses with $95 \%$ CI, (B) calculate the overall $\mathrm{RR}$ and $(\mathrm{C})$ calculate the heterogeneity of the selected studies. A Mantel-Haenszel fixed effect statistical model was used in the meta analyses. ${ }^{23}$

$\mathrm{I}^{2}$ was used to calculate heterogeneity, with the following cut-off statistics used: may not represent important heterogeneity: $0 \%-40 \%$; may represent moderate heterogeneity: 30\%-60\%; may represent substantial heterogeneity: 50\%-90\%; and may represent considerable heterogeneity: $75 \%-100 \% .^{24}$

For the purpose of analysis, the unit for the injury rate used was 'per 1000 match playing hours'. The use of this injury incidence unit is more common across a number of sports. ${ }^{25}$ If an included paper did not have this unit, it was converted. This calculation assumed standard match times per sport with no extra or over time.
A Forest plot was generated to display results and interpreted to determine whether incidence of head injury or concussion differed between contact sport competitions played on natural grass and on artificial turf. The secondary outcome was conducted in the same fashion, identifying studies that specified only 'concussion' as the outcome (figures 2 and 3 ).

\section{Methodological quality}

The Newcastle-Ottawa Quality Assessment Scale was used to evaluate the methodological quality of the selected studies $^{24}$ (table 1). This scale assigns a star (*) per numbered item within the selection and outcome categories. In general, a maximum of four stars (****) can be assigned to selection, two stars (**) for comparability and three stars $(* * *)$ for outcome or exposure. Two reviewers (FO and FH) independently assessed methodological

Table 1 Newcastle-Ottawa Quality Assessment Scale criteria

\begin{tabular}{|c|c|c|c|c|c|c|c|c|c|}
\hline \multirow[b]{2}{*}{ Study } & \multicolumn{4}{|l|}{ Selection } & \multirow{2}{*}{$\begin{array}{l}\text { Comparability } \\
\text { Comparability } \\
\text { of cohorts }\end{array}$} & \multicolumn{3}{|l|}{ Outcomes } & \multirow{2}{*}{$\begin{array}{l}\text { Total } \\
\begin{array}{l}\text { Quality } \\
\text { score }\end{array}\end{array}$} \\
\hline & $\begin{array}{l}\text { Representativeness } \\
\text { of exposed cohort }\end{array}$ & $\begin{array}{l}\text { Selection of } \\
\text { non-exposed } \\
\text { cohort }\end{array}$ & $\begin{array}{l}\text { Ascertainment } \\
\text { of exposure }\end{array}$ & $\begin{array}{l}\text { Outcome not present } \\
\text { at the start of the } \\
\text { study }\end{array}$ & & $\begin{array}{l}\text { Assessment } \\
\text { of } \\
\text { outcomes }\end{array}$ & $\begin{array}{l}\text { Length of } \\
\text { follow-up }\end{array}$ & $\begin{array}{l}\text { Adequacy } \\
\text { of follow-up }\end{array}$ & \\
\hline Bjørneboe et $a /{ }^{35}$ & * & * & * & - & ** & * & * & $\mathrm{n} / \mathrm{a}$ & Good \\
\hline Ekstrand et $\left.a\right|^{36}$ & * & * & * & * & ** & * & * & $\mathrm{n} / \mathrm{a}$ & Good \\
\hline Fuller et $\left.\mathrm{a}\right|^{30}$ & * & * & - & * & ** & * & * & $\mathrm{n} / \mathrm{a}$ & Good \\
\hline Fuller et $\left.a\right|^{31}$ & * & * & - & * & ** & * & * & $\mathrm{n} / \mathrm{a}$ & Good \\
\hline Kordi et $\mathrm{a}^{37}$ & * & * & - & - & * & * & - & $\mathrm{n} / \mathrm{a}$ & Poor \\
\hline Kristenson et al ${ }^{4}$ & * & * & * & * & ** & * & * & $\mathrm{n} / \mathrm{a}$ & Good \\
\hline $\begin{array}{l}\text { Meyers and } \\
\text { Barnhill }^{33}\end{array}$ & * & * & * & * & ** & * & * & $\mathrm{n} / \mathrm{a}$ & Good \\
\hline Meyers $^{27}$ & * & * & * & * & ** & * & * & $\mathrm{n} / \mathrm{a}$ & Good \\
\hline Meyers $^{28}$ & * & * & * & * & ** & * & * & $\mathrm{n} / \mathrm{a}$ & Good \\
\hline Meyers $^{29}$ & * & * & * & * & ** & * & * & $\mathrm{n} / \mathrm{a}$ & Good \\
\hline Ranson et $\mathrm{al}^{32}$ & * & * & - & * & ** & * & * & $\mathrm{n} / \mathrm{a}$ & Good \\
\hline Soligard et $\left.a\right|^{38}$ & - & - & - & * & ** & - & * & $\mathrm{n} / \mathrm{a}$ & Poor \\
\hline
\end{tabular}

Thresholds for converting the Newcastle-Ottawa Scales to AHRQ standards (good, fair and poor).

Good quality: three or four stars in selection domain and one or two stars in comparability domain and two or three stars in outcome/exposure domain.

Fair quality: two stars in selection domain, and one or two stars in comparability domain and two or three stars in outcome/exposure domain.

Poor quality: zero or one star in selection domain or zero stars in comparability domain or zero or one star in outcome/exposure domain.

AHRQ, Agency for Healthcare Research and Quality; n/a, not applicable. 


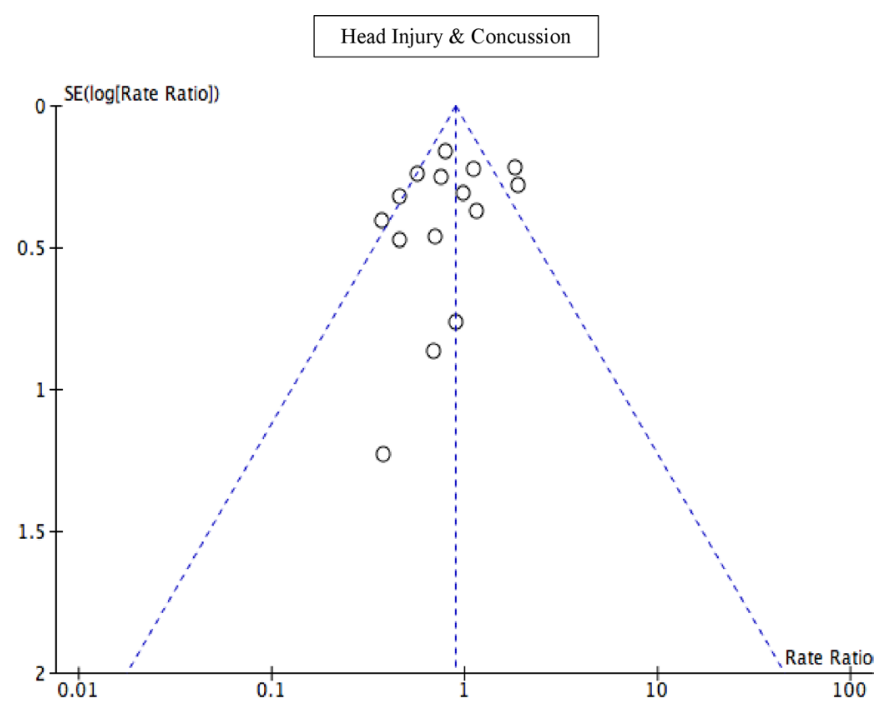

Figure 4 Funnel plot: head injury and concussion rates: artificial turf versus natural grass in competitive contact sports.

quality with a third reviewer (JO) used as an arbitrator in the event of disagreement. As this analysis was concerned with acute head injuries, the 'Adequacy of Follow up of Cohorts' in the outcome section of the scale was not applicable for this review. This resulted in a maximum of only two stars (**) possible in outcome or exposure. The star count per category is then converted to Agency for Healthcare Research and Quality (AHRQ) standards that determines the study to be 'good', 'fair' or 'poor' quality $^{26}$ (see table 1 for criteria). The ability to only assign a maximum of two out of a possible three stars in the outcome section meant that by applying AHRQ standards, the quality of included studies would be underestimated.

\section{Risk of publication bias}

In order to determine the presence of publication bias, funnel plots were considered for both the primary and secondary outcome but only if there were at least 10 studies included in each outcome. If there were fewer than 10 studies, a funnel plot was deemed unreliable to test for publication bias, and therefore, it was not created (as per Cochrane Handbook for Systematic Reviews of Interventions). ${ }^{24}$ Funnel plots were designed via the RevMan V.5.3 software (figure 4). The scatter of points (each point representing included study data) along the plot determined the presence of asymmetry and thus the possible presence of publication bias. Any plot designed was interpreted by both two reviewers (FO and FH). Study heterogeneity was also taken into account.

\section{RESULTS}

\section{Study selection}

The search of electronic databases yielded 56 studies using the key words and limits described in online supplementary appendix 1 . An additional 13 studies were discovered from further review of reference lists. Twenty-seven studies were excluded in the screening process due to duplication. A further 30 studies were excluded based on the relevant selection criteria. Twelve papers fulfilled the criteria for the systematic review describing either head injury or concussion. Eight of the 12 included studies reported on concussion alone. Details of study selection are outlined in figure 1.

\section{Study characteristics}

Included studies were published between 2004 and 2018. Study characteristics are summarised in table 2. Eight studies reported the relevant injuries sustained during soccer, two reported on American football and the final two involved rugby union. Included athletes consisted of a mix of professional and non-professional standard at various stages of progression. Four studies included female athletes, one of these reported on female athletes only (table 2).

A combined total of 260 head injuries and concussions occurred from a total of 91337 match playing hours on artificial turf. This compared with 755 head injuries and concussions sustained on natural grass from 220201 match playing hours. The secondary outcome, concussion only, revealed 145 concussions from a total of 67825 match playing hours on artificial turf compared with 234 concussions from a total of 94408 match playing hours on natural grass.

\section{Methodological quality assessment}

The quality assessment of the selected studies is presented in table 1 using the Newcastle-Ottawa Quality Assessment Scale. As per $\mathrm{AHRQ}^{26}$ standards, 10 studies were classified as 'Good' quality and 2 studies as 'Poor' quality (see table 1 for individual domain scores).

\section{Risk of publication bias}

A funnel plot was generated via the RevMan V.5.3 software to determine the presence of asymmetry for the primary outcome only. Figure 4 assesses publication bias risk, via a funnel plot for head injury and concussion. It demonstrates that the majority of the included studies had large sample sizes with high precision and small SE. This funnel plot was asymmetric due to the absence of small studies. This may indicate publication bias. When assessing this asymmetric funnel plot for head injuries and concussion, its heterogeneity $\left(\mathrm{I}^{2}=61 \%\right)$ was taken into account.

For concussion only, eight studies were included in this meta analysis. As per Cochrane Handbook for Systematic Reviews of Interventions, at least 10 studies should be included for a funnel plot to be deemed reliable in differentiating true asymmetry from chance. ${ }^{24}$ For this reason, a funnel plot was not designed for concussion only.

\section{Summary of effect sizes}

When combining all competitive contact sports together, the 12 selected studies reveal a lower rate of head injury and concussion on artificial turf compared with natural grass ( $\mathrm{RR}=0.89,95 \%$ CI 0.77 to 1.04$)$. The concussion-only 


\begin{tabular}{|c|c|c|c|c|c|c|}
\hline Reference & $\begin{array}{l}\text { Year of } \\
\text { publication }\end{array}$ & Sport & $\begin{array}{l}\text { Participants: } \\
\text { country of origin }\end{array}$ & Gender & Subjects: athlete level & Relevant outcome \\
\hline Bjørneboe et $a l^{35}$ & 2010 & Soccer & Norway & Male & $\begin{array}{l}\text { First team players from one } \\
\text { club in Norwegian Professional } \\
\text { League. }\end{array}$ & Concussion \\
\hline Ekstrand et $a l^{36}$ & 2011 & Soccer & $\begin{array}{l}\text { Sweden, Norway, } \\
\text { Netherlands, } \\
\text { Finland, Ireland, } \\
\text { Scotland, } \\
\text { Switzerland and } \\
\text { Austria }\end{array}$ & $\begin{array}{l}\text { Male and } \\
\text { female }\end{array}$ & $\begin{array}{l}\text { Elite first team players from clubs } \\
\text { across countries in Europe. }\end{array}$ & Concussion \\
\hline Fuller et $a l^{30}$ & 2007 & Soccer & USA & $\begin{array}{l}\text { Male and } \\
\text { female }\end{array}$ & $\begin{array}{l}\text { American college and university } \\
\text { teams on NCAA Injury } \\
\text { Surveillance System. }\end{array}$ & Head/neck injury \\
\hline Fuller et $a l^{31}$ & 2010 & Rugby union & $\begin{array}{l}\text { UK and Hong } \\
\text { Kong }\end{array}$ & Male & $\begin{array}{l}6 \text { teams from Division One } \\
\text { Rugby Hong Kong. } \\
2 \text { teams from English } \\
\text { Premiership. }\end{array}$ & Concussion \\
\hline Kordi et $a l^{37}$ & 2011 & Soccer & Iran & Male & $\begin{array}{l}\text { Non-professional soccer players } \\
\text { - local league in Iran. }\end{array}$ & $\begin{array}{l}\text { Head/face/neck } \\
\text { injury }\end{array}$ \\
\hline Kristenson et $a l^{4}$ & 2013 & Soccer & $\begin{array}{l}\text { Sweden and } \\
\text { Norway }\end{array}$ & Male & $\begin{array}{l}\text { Professional soccer players in } 12 \\
\text { premier league teams in Norway } \\
\text { and Sweden. }\end{array}$ & Concussion \\
\hline $\begin{array}{l}\text { Meyers and } \\
\text { Barnhill }^{33}\end{array}$ & 2004 & $\begin{array}{l}\text { American } \\
\text { football }\end{array}$ & USA & Male & $\begin{array}{l}8 \text { USA high school football } \\
\text { teams. }\end{array}$ & Concussion \\
\hline Meyers et $\mathrm{al}^{27}$ & 2010 & $\begin{array}{l}\text { American } \\
\text { football }\end{array}$ & USA & Male & 24 American university teams. & Concussion \\
\hline Meyers et $\left.a\right|^{28}$ & 2013 & Soccer & USA & Female & $\begin{array}{l}13 \text { USA university teams from } \\
\text { Division } 1 \mathrm{~A} \text {. }\end{array}$ & Concussion \\
\hline Meyers et $a l^{29}$ & 2016 & Soccer & USA & Male & $\begin{array}{l}11 \text { USA university Division } 1 \mathrm{~A} \\
\text { soccer teams. }\end{array}$ & Concussion \\
\hline Ranson et $a^{32}$ & 2018 & Rugby union & UK & Male & 2 UK professional rugby teams. & Head injury \\
\hline Soligard et $a l^{38}$ & 2012 & Soccer & Norway & $\begin{array}{l}\text { Male and } \\
\text { female }\end{array}$ & $\begin{array}{l}\text { Youth soccer teams } \\
\text { ages } 13-19 \text { years. }\end{array}$ & Head injury \\
\hline
\end{tabular}

rate on artificial turf drops further when assessing its included eight studies ( $\mathrm{RR}=0.72,95 \% \mathrm{CI} 0.58$ to 0.89 ) (figures 2 and 3).

The effect sizes for the head injury and concussion meta-analysis was tested for heterogeneity, with $\chi^{2}=35.77$, $\mathrm{df}=14$ (figure 2). A further statistical test revealed substantial heterogeneity $\left(\mathrm{I}^{2}=61 \%\right)$. Analysis of heterogeneity for concussion only revealed $\chi^{2}=8.84, \mathrm{df}=8$. For these eight studies, substantially less heterogeneity was seen $\left(\mathrm{I}^{2}=10 \%\right)$ (figure 3$)$.

\section{Gender}

Four of the included studies reported outcome data for female athletes. The rates of head injuries or concussion in female athletes did not differ between artificial turf or natural grass ( $\mathrm{RR}=1.09,95 \% \mathrm{CI} 0.80$ to 1.48$)$. There was heterogeneity between these four studies, $\mathrm{I}^{2}=52 \%$ $\left(\chi^{2}=6.24, \mathrm{df}=3\right)$.

\section{Individual sports}

The two included rugby studies showed fewer head injuries or concussions occurring on artificial turf $(R R=0.56$,
$95 \%$ CI 0.35 to 0.88$)$. There was no heterogeneity between these two studies, $\mathrm{I}^{2}=0 \%\left(\chi^{2}=0.1, \mathrm{df}=1\right)$. Two of the American football studies (both having concussion as the outcome) also demonstrated fewer concussions on artificial turf ( $\mathrm{RR}=0.72,95 \%$ CI 0.54 to 0.96$)$ with considerable heterogeneity between them, $\mathrm{I}^{2}=67 \% \quad\left(\chi^{2}=3.00\right.$, $\mathrm{df}=1)$. The included eight soccer studies showed no difference in head injury or concussion rates on either playing surface ( $\mathrm{RR}=1.06,95 \% \mathrm{CI} 0.88$ to 1.27$)$ and may represent substantial heterogeneity, $I^{2}=57 \% \quad\left(\chi^{2}=23.44\right.$, $\mathrm{df}=10){ }^{24}$

\section{Summary of meta-analysis}

The meta-analyses and forest plots are shown in figures 2-4, with a contingency table of events in online supplementary appendix 2 .

\section{DISCUSSION}

\section{Summary of findings}

This systematic review assessed current literature to determine the concussion and head injury injury rate in 
competitive contact sports when played on artificial turf compared with natural grass. The result of the review and meta analysis suggest that the rate of concussion or head injury is less on artificial turf in competitive contact sports. This suggestion, however, should be weighed up against potential limitations in conducting this systematic review, most notably heterogeneity, sport-specific comparison, units of injury and outcome measures (discussed further). Meta analysis also took place examining concussion only as a secondary outcome that had a lower rate on artificial turf. Other specific subgroups of the review included: assessing individual sports and assessing female athletes.

\section{Sport-specific results}

The 12 papers from the review involved three sports: soccer (eight papers), rugby union (two papers) and American football (two papers).

Differences were noted between each individual sport in the rate of head injuries or concussions when comparing artificial turf and natural grass. Combining 'contact sports' as one entity may be an issue. For example, soccer and American football are both considered contact sports. However, considering the more combative nature of American football, it may be difficult to accept that the head injury or concussion rates for both these sports should be directly compared.

Two papers were included for American football, both having concussion as the outcome and both showing fewer concussions on artificial turf. It is difficult to determine if these results truly reflect the concussion rate for this sport. Both papers were published by the same author-one reviewing high school football, the other college football. ${ }^{27}{ }^{28}$ It is unknown if these results would correlate to all American football, including professional American football.

The eight included studies for soccer demonstrated no statistical difference with regards to head injury or concussion rates between the two playing surfaces. As seen in the forest plot in figure 2, only two of the eight studies did not cross the line of no effect (Meyers ${ }^{29}$ and Fuller et $\left.a l^{30}\right)$. They had, however, contrasting results, both reviewing university soccer players. Meyers ${ }^{29}$ demonstrated significantly more concussions occurring on natural grass compared with artificial turf. ${ }^{29}$ Fuller et $a l^{30}$ showed higher concussion rates in soccer players who played on artificial turf. ${ }^{30}$ The reason for these contrasting results is unclear.

In rugby, the two included studies showed a lower concussion or head injury rate on artificial turf. Fuller et $a l \mathrm{~s}^{31}$ study diagnosed far fewer concussions compared with Ranson et $a l^{32}$ head injuries. Fuller et $a l^{31}$ documented only three concussions (one on artificial turf, two on grass) out of 2400 match playing hours. None, however, were due to contact with the playing surface. ${ }^{31}$ Ranson $e t a l \mathrm{~s}^{32}$ paper demonstrated a higher incidence of head injuries sustained on natural grass compared with artificial turf (23.9vs 13.5 per 1000 match playing hours). This incidence is far higher than the three concussions documented in Fuller et al's paper. Between the time of Fuller et al s publication in 2010 and Ranson et $a l$ s in 2018, a significant campaign and awareness of recognising head injuries and concussion in rugby union had occurred worldwide. ${ }^{12}$ This may account for the significant difference in head injury and concussion incidence. As per the meta-analysis, the paper by Ranson et al was weighted more significantly than that by Fuller et al (96.3\% vs $3.7 \%)$.

\section{Quality of evidence}

\section{Heterogeneity of meta-analyses}

The meta-analysis confirmed some heterogeneity among the 12 studies for head injury and concussion $\left(I^{2}=61 \%\right)$. This would imply that the rate ratio $(\mathrm{RR}=0.89,95 \% \mathrm{CI}$ 0.77 to 1.04 ) for this outcome would not be valid.

The eight papers for concussion only reveal a significantly heterogeneity $\left(I^{2}=10 \%\right)$. This implies a valid value for the rate ratio of concussion played on artificial turf compared with natural grass in competitive contact sports $(\mathrm{RR}=0.72,95 \% \mathrm{CI} 0.58$ to 0.89$)$.

\section{Injury incidence rate (IIR)}

Four of the 12 chosen studies for head injuries and concussion displayed different injury incidence units to the remaining. All of these four studies had the same lead author, Meyers. ${ }^{27-29} 33$ The unit used in these studies was IIR. IIR is defined as the number of injuries divided by the total number of matches multiplied by 10 . These values were converted to per 1000 match playing hours in line with the remaining studies. This was calculated by making the assumption that the matches played in the four studies did not have overtime or extra time. The lead author was asked directly about this issue. He did not see it affecting the overall outcome.

\section{Comparison with other reviews}

Few studies have directly examined the risk of concussion or head injury when played on artificial turf in contact sport. Concussion has become a very topical issue in this domain due to the apparent significant rise in the rate of sports related concussion. ${ }^{9}$ The reasons for this appear to be multifactorial. This includes better public awareness about concussion, strict protocols being implemented and so on. ${ }^{932}$ However, with a variety of more sports using artificial turf for playing matches, it is reasonable to investigate any link between artificial turf use and concussion risk.

\section{Study strengths and limitations \\ Artificial turf}

For the included studies in this systematic review, there was no known consistency in the artificial turf type. The maintenance schedule of each artificial turf was unknown as was its specific performance parameters, most notably Head Injury Criterion (HIC). HIC is a mathematical model of determining the risk of concussion when the head comes into contact with the playing surface. From 
it, a critical fall height value can be assigned to each synthetic surface. ${ }^{7}$ These unknown variables could have played a part in the outcome rates.

\section{State of play and surface type}

The manner in which each sport is played on artificial turf (compared with natural grass) is an important point to consider.

In soccer, evidence exists of different tactics and play patterns occurring on artificial turf, with less tackles and shorter passes being noted. ${ }^{6}$ In rugby, most concussions occur in the tackle, ${ }^{34}$ yet it is not established if more tackles occur on natural grass compared with artificial turf. If this was the case, the rate of concussion on artificial turf may not be solely due to its surface properties as opposed to the difference in which the game is played on that surface.

\section{CONCLUSION}

This systematic review demonstrates an overall lower concussion and head injury rate occurring on artificial turf in competitive contact sports combined, yet when assessing the sports (soccer, American football and rugby) individually, the link between head injury and concussion with playing surface type is not as clear.

Future research in this area would be important to ascertain reasons for this result. Further examination on what other factors exist that could lead to lower head injury and concussion rates on artificial turf in contact sports should be established. This may include: number of collisions on artificial turf, the incidence of surface to head contact, the maintenance of the artificial turf as well as its surface properties including temperature and HIC.

Contributors F0 and NA contributed to the development of the research question. F0 performed the literature search. F0 and FH performed the study selection, methodological quality and assessment, data extraction and methodological quality assessment. J0 and FH edited the review. All authors approved the final manuscript.

Funding The authors have not declared a specific grant for this research from any funding agency in the public, commercial or not-for-profit sectors.

\section{Competing interests None declared.}

Patient consent for publication Not required.

Provenance and peer review Not commissioned; externally peer reviewed.

Data availability statement Data are available upon request.

Open access This is an open access article distributed in accordance with the Creative Commons Attribution Non Commercial (CC BY-NC 4.0) license, which permits others to distribute, remix, adapt, build upon this work non-commercially, and license their derivative works on different terms, provided the original work is properly cited, appropriate credit is given, any changes made indicated, and the use is non-commercial. See: http://creativecommons.org/licenses/by-nc/4.0/.

ORCID iD

Frank 0' Leary http://orcid.org/0000-0002-4283-7031

\section{REFERENCES}

1 Definitions.net [Internet]. Available: https://www.definitions.net [Accessed 21 Nov 2019].

2 Skovron ML, Levy IM, Agel J. Living with artificial grass: a knowledge update. Part 2: epidemiology. Am J Sports Med 1990;18:510-3.
3 Powell JW, Schootman M. A multivariate risk analysis of selected playing surfaces in the National football League: 1980 to 1989. An epidemiologic study of knee injuries. Am J Sports Med 1992;20:686-94.

4 Kristenson K, Bjørneboe J, Waldén M, et al. The Nordic football injury audit: higher injury rates for professional football clubs with third-generation artificial turf at their home venue. $\mathrm{Br} J$ Sports Med 2013;47:775-81.

5 Jastifer JR, McNitt AS, Mack CD, et al. Synthetic turf: history, design, maintenance, and athlete safety.. Sports Health 2019;11:84-90.

6 Andersson $\mathrm{H}$, Ekblom B, Krustrup P. Elite football on artificial turf versus natural grass: movement patterns, technical Standards, and player impressions. J Sports Sci 2008;26:113-22.

7 World Rugby Player Welfare - Putting Players First: ONE TURF CONCEPT, 2017. Available: http://playerwelfare.worldrugby.org/? subsection=78 [Accessed 6 May 2019].

8 Charalambous L, von Lieres Und Wilkau HC, Potthast W, et al. The effects of artificial surface temperature on mechanical properties and player kinematics during landing and acceleration. J Sport Health Sci 2016;5:355-60.

9 McCrory P, Meeuwisse W, Dvořák J, et al. Consensus statement on concussion in sport-the $5^{\text {th }}$ international conference on concussion in sport held in Berlin, October 2016. Br J Sports Med 2017:51:838-47.

10 Langlois JA, Rutland-Brown W, Wald MM. The epidemiology and impact of traumatic brain injury: a brief overview. J Head Trauma Rehabil 2006;21:375-8.

11 Daneshvar DH, Nowinski CJ, McKee AC, et al. The epidemiology of sport-related concussion. Clin Sports Med 2011;30:1-vii.

12 Baldwin GT, Breiding MJ, Comstock RD. Epidemiology of sports concussion in the United States. In: Hainline B, Stern RA, eds. Handbook of clinical neurology. Oxford: Elsevier, 2018: 63-74.

13 Meyers MC. Incidence, mechanisms, and severity of game-related high school football injuries across artificial turf systems of various Infill weight. Orthopaedic Journal of Sports Medicine 2019;2.

14 Clark MD, Asken BM, Marshall SW, et al. Descriptive characteristics of concussions in national football League games, 2010-2011 to 2013-2014. Am J Sports Med 2017:45:929-36.

15 Moher D, Liberati A, Tetzlaff J, et al. Preferred reporting items for systematic reviews and meta-analyses: the PRISMA statement. PLoS Med 2009;6:e1000097.

16 Stroup DF, Berlin JA, Morton SC, et al. Meta-Analysis of observational studies in epidemiology: a proposal for reporting. meta-analysis of observational studies in epidemiology (moose) group. JAMA 2000;283:2008-12.

17 Morin M, Langevin P, Fait P. Cervical spine involvement in mild traumatic brain injury: a review. J Sports Med 2016;2016:1590161.

18 Zuckerman SL, Kerr ZY, Yengo-Kahn A, et al. Epidemiology of sports-related concussion in NCAA athletes from 2009-2010 to 2013-2014: incidence, recurrence, and mechanisms. Am J Sports Med 2015:43:2654-62.

19 Covassin T, Swanik CB, Sachs ML. Sex differences and the incidence of concussions among collegiate athletes. J Athl Train 2003;38:238-44.

20 Hootman JM, Dick R, Agel J. Epidemiology of collegiate injuries for 15 sports: summary and recommendations for injury prevention initiatives. J Athl Train 2007;42:311-9.

21 Higgins JPT, Thomas J, Chandler J, et al. Cochrane Handbook for Systematic Reviews of Interventions version 6.0 (updated July 2019). Cochrane, 2019. Available: www.training.cochrane.org/handbook

22 Review Manager (RevMan) [Computer program]. Version 5.3. Copenhagen: The Nordic Cochrane Centre, The Cochrane Collaboration, 2014

23 Efthimiou O. Practical guide to the meta-analysis of rare events. Evid Based Ment Health 2018;21:72-6.

24 Higgins JPT, Green S. Cochrane Handbook for Systematic Reviews of Interventions Version 5.1.0 [updated March 2011]. The Cochrane Collaboration, 2011. Available: www.handbook.cochrane.org

25 Phillips LH. Sports injury incidence. Br J Sports Med 2000;34:133-6.

26 Agency for Healthcare Research and Quality [Internet]. Rockville. Available: https://www.ahrq.gov

27 Meyers MC. Incidence, mechanisms, and severity of game-related College football injuries on FieldTurf versus natural grass: a 3-year prospective study. Am J Sports Med 2010;38:687-97.

28 Meyers MC. Incidence, mechanisms, and severity of matchrelated collegiate women's soccer injuries on FieldTurf and natural grass surfaces: a 5-year prospective study. Am J Sports Med 2013;41:2409-20.

29 Meyers MC. Incidence, mechanisms, and severity of MatchRelated collegiate men's soccer injuries on FieldTurf and natural 
grass surfaces: a 6-year prospective study. Am J Sports Med 2017;45:708-18.

30 Fuller CW, Dick RW, Corlette J, et al. Comparison of the incidence, nature and cause of injuries sustained on grass and new generation artificial turf by male and female football players. Part 2: training injuries. Br J Sports Med 2007;41 Suppl 1:i27-32.

31 Fuller CW, Clarke L, Molloy MG. Risk of injury associated with rugby Union played on artificial turf. J Sports Sci 2010;28:563-70.

32 Ranson C, George J, Rafferty J, et al. Playing surface and UK professional rugby Union injury risk. J Sports Sci 2018;36:2393-8.

33 Meyers MC, Barnhill BS. Incidence, causes, and severity of high school football injuries on FieldTurf versus natural grass: a 5-year prospective study. Am J Sports Med 2004;32:1626-38.

34 England RFU. England Professional Rugby Injury Surveillance Project Steering Group, 2017 - 2018 Season Report, 2018. Available: https://www.englandrugby.com/participation/playing/player-welfarerugby-safe/rugbysafe-research [Accessed 2 Oct 2019].

35 Bjørneboe J, Bahr R, Andersen TE. Risk of injury on third-generation artificial turf in Norwegian professional football. Br J Sports Med 2010;44:794-8.

36 Ekstrand J, Hägglund M, Fuller CW. Comparison of injuries sustained on artificial turf and grass by male and female elite football players. Scand J Med Sci Sports 2011;21:824-32.

37 Kordi R, Hemmati F, Heidarian $\mathrm{H}$, et al. Comparison of the incidence, nature and cause of injuries sustained on dirt field and artificial turf field by amateur football players. Sports Med Arthrosc Rehabil Ther Technol 2011;3:3.

38 Soligard T, Bahr R, Andersen TE. Injury risk on artificial turf and grass in youth tournament football. Scand J Med Sci Sports 2012;22:356-61. 